DOI: $10.22481 /$ recuesb.v8i14.7824

\title{
OFICINAS TEMÁTICAS SOBRE QUÍMICA E CIDADANIA: PESQUISA, ENSINO E EXTENSÃO
}

\author{
THEMATIC WORKSHOP ON CHEMISTRY AND CITIZENSHIP: RESEARCH, \\ EDUCATION AND EXTENSION
}

\author{
Tathiane Milaré ${ }^{1}$ \\ Vitória Martoni Bueno Barbosa ${ }^{2}$ \\ Nara Flaviane Pistarini ${ }^{3}$ \\ Ana Carolina Dias de Oliveira ${ }^{4}$
}

\begin{abstract}
Resumo: Este trabalho tem como objetivo relatar e discutir as atividades desenvolvidas em oficinas temáticas sobre Química e cidadania em um projeto de extensão da Universidade Federal de São Carlos, campus Araras. O projeto de extensão consistiu em elaborar e oferecer à comunidade em geral oficinas que relacionassem conhecimentos químicos a aspectos sociais, políticos, econômicos e ambientais dos temas química forense, cosméticos, alimentação e poluição ambiental. É relatado o desenvolvimento de quatro oficinas que contaram com diferentes estratégias e metodologias de ensino, pautadas na pesquisa em ensino de química e nos pressupostos da abordagem Ciência, Tecnologia e Sociedade. Os resultados apontam para a articulação entre ensino, pesquisa e extensão e para as contribuições na formação docente das monitoras envolvidas. Conclui-se que as atividades realizadas permitiram uma abordagem diferenciada dos conhecimentos químicos, despertando o interesse da comunidade externa e interna à universidade pelos temas tratados.
\end{abstract}

Palavras-chave: Abordagem temática. Ciência-Tecnologia-Sociedade. Ensino de química.

Abstract: This paper presents and discusses the activities about the thematic workshops on chemistry and citizenship in the scope of an extension project at the Federal University of São Carlos. The extension project consisted in developing workshops for the community that approached scientific, social, political, financial and environmental aspects of the chemical, cosmetic, food and environmental issues. It is reported the development of four workshops that

\footnotetext{
${ }^{1}$ Doutora em Ensino de Ciências. Professora do Departamento de Ciências da Natureza, Matemática e Educação, da Universidade Federal de São Carlos (UFSCar), campus Araras, São Paulo, Brasil. Participante do Grupo de Pesquisa Educação em Ciências da Natureza. E-mail: tmilare @ufscar.br

${ }^{2}$ Licenciada em Química, pela Universidade Federal de São Carlos (UFSCar), campus Araras, São Paulo, Brasil. E-mail: vimbbarbosa16@gmail.com

${ }^{3}$ Licenciada em Química, pela Universidade Federal de São Carlos (UFSCar), campus Araras, São Paulo, Brasil. E-mail: nara_pistarini@hotmail.com

${ }^{4}$ Mestre em Educação em Ciências e Matemática; Licenciada em Química, ambos pela Universidade Federal de São Carlos (UFSCar), campus Araras, São Paulo, Brasil. Participante do Grupo de Pesquisa Educação em Ciências da Natureza. E-mail: oliveiradiasac@gmail.com
} 
had different strategies and teaching methodologies, in the area of chemical education and in the Science-Technology-Society perspective. The results show the articulation between teaching, research and extension and the contributions to the teacher education of the students involved. It is concluded that the activities allowed an innovative approach to chemical knowledge, arousing the interest of the external and internal community at the university for the themes.

Keywords: Thematic approach. Science-Technology-Society. Chemical education.

\section{Introdução}

Um dos desafios da docência no Ensino Superior, principalmente nas instituições públicas de ensino brasileiras, é o desenvolvimento de ações que articulem a pesquisa, o ensino e a extensão de forma a contribuir com a função da universidade de obedecer ao princípio de indissociabilidade entre estas três atividades. Em cursos de licenciatura, a articulação dessas atividades contribui para a formação profissional de forma peculiar, pois possibilita a formação de professores comprometidos com esta perspectiva e com o papel social de sua profissão, diminuindo as distâncias entre a pesquisa e a sala de aula, naturalizando a atuação do professorpesquisador. Determinadas atividades de extensão estabelecem, ainda, parcerias com a educação básica, o contato com atividades de ensino e materiais, que possibilitam o reconhecimento de problemáticas e situações inerentes ao trabalho docente, em momentos e formas diferenciadas do estágio supervisionado e outras atividades curriculares.

No entanto, para que essa formação seja promovida, é necessário que as atividades de extensão sejam concebidas em uma perspectiva que ultrapasse a ideia de um processo de estender ou levar o conhecimento técnico, produzido e acabado na universidade. Nesse sentido, a relação entre a comunidade e a universidade não é unívoca, mas estabelecida pelo diálogo, pela troca e construção de saberes. No caso de atividades relacionadas tanto ao ensino quanto à formação de professores, a participação dos envolvidos na construção dos conhecimentos é essencial para promover a compreensão da natureza e do processo de construção dos conhecimentos científicos.

Assim, a extensão universitária "configura-se como um importante espaço de prática social e aprendizagem profissional no âmbito acadêmico, integrando dimensões investigativas e interventivas" (SANTOS, 2014, p. 162). Com ações envolvendo estudantes de licenciatura e 
situações de ensino-aprendizagem, a extensão se constitui como um espaço de formação docente e de construção e difusão de práticas de ensino inovadoras e fundamentadas na pesquisa, que podem auxiliar na superação de obstáculos ou na resolução de problemas encontrados no contexto escolar.

No que se refere ao ensino de química, por exemplo, muitas dificuldades e preconcepções em relação à Química são conhecidas pelos professores e pesquisadores da área. Comumente, a Química é associada a fórmulas, nomenclaturas e estruturas difíceis, compreendidas apenas por pessoas excepcionalmente inteligentes. Essas ideias estão vinculadas a visões descontextualizadas, elitistas, a-problemáticas e a-teóricas da Ciência (CACHAPUZ et al., 2005), muitas vezes decorrentes do próprio ensino.

Esse contexto revela a necessidade da renovação no ensino de ciências da educação básica e, ainda, de atividades, também fora da escola, em processos de educação não-formal, que provoquem a reflexão crítica sobre estas visões, auxiliando na compreensão da Química como uma ciência dinâmica e de grande importância para a formação de cidadãos críticos. Segundo Gohn (2006, p. 28), "a educação não-formal é aquela que se aprende "no mundo da vida", via os processos de compartilhamento de experiências, principalmente em espaços e ações coletivos cotidianas”. Assim, diferencia-se da educação formal, sistematizada e desenvolvida na escola, e da educação informal, decorrente da família, amigos, e da convivência de outros grupos sociais. Mesmo tendo uma participação não obrigatória, a educação nãoformal possui uma intencionalidade, principalmente, no que se refere à formação de cidadãos participativos (GOHN, 2006).

Dentre as diversas possibilidades na promoção da educação não-formal está o desenvolvimento de oficinas temáticas, uma vez que é constituída por situações de aprendizagem com intencionalidade, não é obrigatória, nem seriada, e permite a construção coletiva de determinados conhecimentos que transformam a visão de mundo dos participantes. Para Marcondes, as oficinas podem representar:

[...] um local de trabalho em que se buscam soluções para um problema a partir dos conhecimentos práticos e teóricos. Tem-se um problema a resolver que requer competências, o emprego de ferramentas adequadas e, às vezes, de improvisações, pensadas na base de um conhecimento. Requer trabalho em equipe, ação e reflexão. (MARCONDES, 2008, p. 68) 
Assim, as oficinas podem ser elaboradas em torno de temas sociais (por isso, a denominação oficina temática), que possam ser mais bem compreendidos por meio de conhecimentos científicos. Por sua vez, os conhecimentos científicos podem ser abordados nestas oficinas com o uso de metodologias e estratégias de ensino diferenciadas, não sendo limitadas pelo tempo de uma ou duas aulas, por exemplo, como ocorre no ensino formal. Essas características das oficinas temáticas condizem com a perspectiva de extensão universitária como espaço de aprendizagem da docência no âmbito dos cursos de licenciatura.

Neste contexto, o objetivo deste trabalho é relatar e discutir as atividades desenvolvidas em oficinas temáticas sobre Química e Cidadania em um projeto de extensão da Universidade Federal de São Carlos, campus Araras. O projeto de extensão consiste em elaborar e oferecer à comunidade em geral oficinas que relacionem conhecimentos químicos aos aspectos sociais, políticos, econômicos e ambientais, enfatizando o tratamento de um determinado tema. Desde sua criação, em 2016, foram desenvolvidas oficinas sobre os temas química forense, cosméticos, alimentação e poluição ambiental.

\section{O projeto}

O projeto "Oficinas temáticas sobre Química e cidadania" foi criado em 2016 e, desde então, atuaram na criação das oficinas quatro estudantes do curso de Licenciatura em Química como bolsistas de atividade de extensão (uma por ano) e outros cinco como voluntários, orientados por uma docente e pesquisadora da área de ensino de química. Além de uma bolsa por ano, com duração de seis meses, o projeto contou com um apoio financeiro de menos de trezentos reais em seu primeiro ano, obtido por meio de edital institucional de apoio a atividades de extensão. Durante seus dois primeiros anos de existência, foram oferecidas 19 oficinas, com quatro temáticas diferentes, totalizando cerca de 300 participantes. Algumas dessas oficinas foram realizadas em uma escola pública de educação básica e outras fizeram parte da programação de semanas acadêmicas de diferentes universidades, em três estados diferentes.

As oficinas desvinculadas da escola e das semanas acadêmicas foram divulgadas em redes sociais na internet e eram abertas para qualquer pessoa que tivesse interesse, necessitando, apenas, realizar a inscrição on-line para as turmas em prazos estabelecidos. Durante a inscrição, os interessados forneciam alguns dados pessoais, como nome, endereço, idade e escolaridade, com o intuito de caracterizar um perfil dos participantes. Além desses dados, também eram

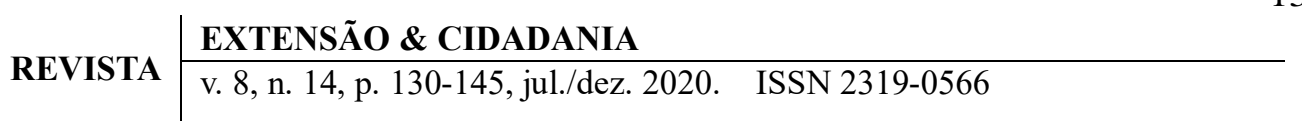


solicitadas respostas a algumas questões sobre o interesse pela oficina e conhecimentos prévios sobre o tema. Isso permitia conhecer um pouco sobre os interesses do público participante.

As oficinas tiveram duração entre 3 e 4 horas, dependendo da participação das pessoas e do tempo utilizado no desenvolvimento das atividades práticas. O espaço utilizado na universidade para sua realização foi o Laboratório Interdisciplinar de Formação de Educadores (LIFE) da UFSCAr-Araras, que conta com três salas e um laboratório, voltados para o desenvolvimento de atividades relacionadas à formação docente. Em todas as oficinas, houve apresentações, realização de experimentos e de outras atividades práticas e exibição de vídeos, que problematizavam questões acerca do tema, estimulando os participantes para o debate. A seguir, serão descritas as oficinas para cada um dos temas desenvolvidos.

\section{Química forense}

O tema tratado nas primeiras oficinas do projeto foi "Química Forense", inspirado pelo trabalho de Silva e Rosa (2013) e Cruz et al. (2016). A fundamentação de sua criação baseouse nos princípios da Alfabetização Científica, considerando as perspectivas prática, cívica, cultural e econômica ou profissional (SHEN, 1975 apud LORENZETTI; DELIZOICOV, 2001; MARCO, 2000; FOUREZ, 2005). Desse modo, foram propostas atividades que contemplassem aspectos sociais, políticos, culturais, entre outras, promovendo a compreensão de processos sob o ponto de vista científico, a tomada de decisão e o contato com a química forense, área específica da Química.

No início da oficina, os participantes e integrantes do projeto de extensão eram apresentados, assim como uma breve exposição sobre como seriam realizadas as atividades. Após as apresentações iniciais, foi exibido um vídeo denominado "Tudo se Transforma, História da Química, Química Forense” (2012), que aborda aspectos históricos da química forense, algumas técnicas utilizadas e casos em que as investigações tiveram diferentes interpretações, como nos estudos sobre a morte de Napoleão Bonaparte e o caso do ex-jogador de futebol americano Orenthal James Simpson.

A partir do vídeo, foram discutidas sobre as possibilidades de contaminação da cena do crime e sobre a importância dos cuidados durante a manipulação de provas nas investigações. Esses aspectos seriam importantes nas etapas seguintes, de caráter mais prático, em que foi proposta aos participantes a investigação de um crime simulado por meio de técnicas como 
cromatografia, impressão digital, entre outras. Divididos em grupos, os participantes visitavam a cena de crime simulada, onde deveriam coletar amostras para investigação do caso. Além de analisarem as amostras coletadas na cena de crime, os grupos deveriam analisar as amostras relacionadas aos quatro suspeitos para comparação.

A cena do crime foi simulada em uma sala de reuniões e continha a demarcação do corpo feita com fita crepe, um porta-retratos, uma agenda e as amostras que seriam coletadas por cada grupo. As amostras eram pedaços de papel com mensagem secreta e digitais, foto da vítima com o criminoso rasgada e amassada, saquinhos plástico com amostras de fruta e papel de filtro com uma bolinha pintada de canetinha hidrocor preta. As amostras dos suspeitos eram da mesma natureza, mas com características distintas como, por exemplo, os pedaços de papéis tinham diferentes caligrafias e as bolinhas eram de diferentes cores, remetendo a cada um dos quatro suspeitos.

Para investigar o crime e identificar o criminoso entre os suspeitos, os participantes deveriam realizar os seguintes procedimentos para análise das amostras: revelação da impressão digital com uso de uma mistura de óxido de ferro, amido de milho e "negro de fumo" (SALADA ATÔMICA, 2015); separação do DNA das frutas (LIMA; FRACETO, 2007); cromatografia em papel (LISBÔA, 1998); revelação de mensagens escritas com limão utilizando vela (MANUAL DO MUNDO, 2008) e construção de uma luz negra caseira (MANUAL DO MUNDO, 2015). Todas as atividades práticas foram realizadas em grupos, com materiais de fácil acesso em supermercados e farmácias, e orientadas pelas monitoras das oficinas.

Os procedimentos realizados foram discutidos com os participantes, assim como os conhecimentos químicos envolvidos. Após a construção desses conhecimentos para a compreensão dos processos vivenciados, o papel da ciência e a influência de aspectos políticos e econômicos nas investigações criminais brasileiras foram problematizadas. Para isso, foi apresentado um vídeo jornalístico (FOLHA DE SÃO PAULO, 2016) sobre a morte do extesoureiro da campanha presidencial de Fernando Collor de Melo, Paulo Cézar Farias, em 1996.

\section{Oficina Além da Beleza: consumismo, química e cosméticos}

Esta oficina teve enfoque nas relações Ciência-Tecnologia-Sociedade - CTS (SANTOS; SCHNETZLER, 2015), ou seja, as atividades foram propostas com intuito de promover um processo de ensino-aprendizagem baseado nas inter-relações de explicações científicas,

$$
\begin{array}{l|l}
\multirow{2}{*}{\text { REVISTA }} & \text { EXTENSÃO \& CIDADANIA } \\
\cline { 2 - 3 } & \text { v. 8, n. 14, p. 130-145, jul./dez. 2020. ISSN 2319-0566 }
\end{array}
$$


planejamentos tecnológicos e soluções de problemas com tomadas de decisão sobre assuntos de importância social (SANTOS; MORTIMER, 2001). Por meio dessa abordagem, buscou-se estimular a tomada de decisões dos participantes, envolvendo valores relacionados às necessidades humanas como, por exemplo, o questionamento sobre a necessidade do consumo de cosméticos e a influência do mercado do sistema capitalista no consumismo de produtos que causam impactos na saúde e meio ambiente.

Logo no início da oficina, para estimular a participação ativa e a interação entre os inscritos, uma loja foi simulada em uma mesa, onde foram dispostas imagens de cosméticos com diversas finalidades, em formato de cartas, e os participantes poderiam realizar suas "compras", recolhendo as cartas que representavam os produtos desejados para consumo. Os produtos adquiridos foram guardados para discussão em um momento posterior.

Em seguida, foram exibidas diversas propagandas de cosméticos que apresentavam a ideia de poder, fama e sucesso associados ao seu uso, com o intuito de problematizar suas influências em relação à prática do consumismo. A história da utilização e desenvolvimento dos cosméticos também foi abordada por meio de uma apresentação dialogada com os participantes que demonstravam interesse e abordavam questões de seu conhecimento prévio e experiências com o assunto.

As atividades práticas realizadas utilizavam materiais alternativos e de fácil acesso e os participantes tiveram autonomia na realização das práticas, em grupos. Foram desenvolvidas quatro atividades práticas, sob orientação das monitoras: i) Perfumes e seus óleos essenciais que consistiu na extração de óleos essenciais de ervas aromáticas como hortelã e capim limão; ii) Sal no xampu - em que foram realizadas a leitura e a comparação de rótulos de produtos, assim como a medição de $\mathrm{pH}$, comparando as informações fornecidas na embalagem com as obtidas experimentalmente; iii) Por que o sabonete limpa? - em que foi verificada a ação dos sabonetes em mistura de água e óleo e; iv) Protetor Solar protege do que? - que consistiu em observar a pele com e sem protetor solar com uma luz negra feita com o celular.

Após a realização e discussão sobre as atividades práticas realizadas, foi exibido outro vídeo, "A história dos Cosméticos" do projeto intitulado The Story of Stuff (THE STORY OF COSMETICS, 2010), com o objetivo de problematizar o consumismo de cosméticos. Na sequência, foram retomados os produtos adquiridos na loja simulada no início da oficina, e disponibilizadas fichas presentes no guia ambiental da Associação Brasileira da Indústria de Higiene Pessoal, Perfumaria e Cosméticos (ABIHPEC, 2016), que apresentam alguns dos 
resíduos gerados pela produção de diferentes cosméticos. Essa análise e discussão teve a intenção de promover questionamentos em relação aos conhecimentos prévios do que mais está sendo consumido e produzido ao comprar um produto.

Algumas reportagens e notícias sobre o alto consumo de água para produção de cosméticos, a biopirataria, os testes em animais e o consumismo foram lidas e discutidas com o propósito de enfatizar aspectos polêmicos relacionados ao tema da oficina, contribuindo para a reflexão, debate e, consequentemente, para a construção de tomada de decisão e atitude crítica pleiteada pela abordagem CTS.

$\mathrm{Na}$ finalização da oficina, foi proposta a elaboração de uma propaganda em forma de cartaz, levando em consideração tudo o que foi discutido durante a oficina e o que mais os participantes considerassem importante em uma propaganda "ideal" de cosméticos.

\section{A química dos alimentos}

Esta oficina abordou o tema alimentação, assim como a proposta de Pazinato e Braibante (2014), mas com ênfase nos problemas de saúde causados por uma alimentação inadequada, consumismo, influências das propagandas alimentícias, leitura dos rótulos, compreensão das tabelas nutricionais e nutrientes com ajuda dos conceitos químicos. Assim como a oficina sobre cosméticos, foi elaborada com enfoque nas relações Ciência-TecnologiaSociedade (SANTOS; SCHNETZLER, 2015).

No início da oficina, após as apresentações dos participantes e monitoras, houve uma breve explicação sobre o significado e construção da pirâmide alimentar. A pirâmide alimentar foi criada para poder hierarquizar os alimentos, no topo da pirâmide ficam os alimentos menos consumidos e na sua base os mais consumidos. Os participantes foram convidados a construir uma pirâmide alimentar de acordo com seus próprios hábitos alimentares. Essas pirâmides foram socializadas e discutidas.

Em seguida, foram abordados a pirâmide alimentar atual e os processos que levaram a esse modelo (processo histórico), a classificação dos alimentos em in natura, processados e ultraprocessados. Após essa discussão inicial, foi exibido um trecho do documentário "Muito Além do Peso" (2012), que retrata e discute a obesidade infantil do Brasil. O trecho selecionado para este momento conta a história de um menino, no Amazonas, com excesso de peso e sérios problemas de saúde causados por alimentação rica em gorduras e alimentos ultraprocessados.

\footnotetext{
\begin{tabular}{l|l}
\multirow{2}{*}{ REVISTA } & EXTENSÃO \& CIDADANIA \\
\cline { 2 - 3 } & v. 8, n. 14, p. 130-145, jul./dez. 2020. ISSN 2319-0566
\end{tabular}
} 
Na sequência do debate acerca do trecho do documentário, foram discutidos os conhecimentos químicos relacionados à pirâmide alimentar.

Em outro trecho exibido, do mesmo documentário (MUITO ALÉM DO PESO, 2012), é evidenciado o quanto os brasileiros consomem de açúcar por dia e um repórter pergunta para algumas pessoas: "O que é carboidrato? E açúcar é carboidrato?” Os entrevistados respondem que carboidrato é batata, e falam que não sabem se o açúcar é ou não. Nesse contexto, os participantes também foram questionados e explicitaram suas opiniões, que foram relacionadas às explicações químicas dos carboidratos e a ocorrência de diabetes. Além dos carboidratos, foi discutida a composição e propriedades das proteínas e lipídeos.

A parte prática da oficina consistiu na realização de experimentos para verificar a presença de proteína, amido e vitamina C em alimentos; a quantidade de açúcar nos refrigerantes; a densidade de refrigerantes sem açúcar; a transformação do amido presente em biscoitos durante a mastigação; a presença de ferro em cereais; e para investigar a ação do sal no organismo. Todos os experimentos foram realizados pelos próprios participantes e discutidos, considerando não apenas os conhecimentos químicos abordados pelas monitoras como, também, os conhecimentos trazidos por eles. A interpretação das informações contidas nas embalagens dos alimentos também foi trabalhada durante a oficina, abordando as orientações da Agência Nacional de Vigilância Sanitária (ANVISA) e o significado do valor energético, porção, medida caseira, quantidade por porção de carboidratos, proteínas, gorduras, fibras e de sódio do alimento.

Em outro trecho do documentário "Muito além do peso" (2012), a repórter sai às ruas e questiona se as pessoas sabem quanto tem de açúcar em uma lata de refrigerante. Grande parte dos entrevistados não tem ideia e fica surpresa ao se deparar com a representação dessa quantidade de açúcar. No entanto, ao serem questionadas sobre a continuidade do consumo de refrigerantes, as crianças respondem repetindo o slogan de uma marca famosa de refrigerantes. Esse trecho foi utilizado para problematizar o papel das propagandas e o consumismo relacionado aos hábitos alimentares. Outros excertos suscitaram discussões sobre o consumo de refrigerantes por bebês, o consumo de alimentos ultraprocessados por comunidades tradicionais e a quantidade de conservantes e outras substâncias artificiais em grande parte dos alimentos que chama a atenção devido a suas embalagens coloridas, com personagens televisivos e propaganda. 
Na parte final da oficina, foi retomada a primeira atividade, da pirâmide alimentar, no entanto, dessa vez, os participantes foram convidados a analisar sua alimentação, baseando-se nas discussões da oficina. Foi exibido um vídeo comparando os impactos de hábitos saudáveis e não saudáveis no dia a dia das pessoas.

\section{O que vai pelo ralo: rastros ambientais de produtos que consumimos}

O desenvolvimento das atividades dessa oficina baseou-se nos Três Momentos Pedagógicos (DELIZOICOV; ANGOTTI; PERNAMBUCO, 2011) e, assim como as demais, teve enfoque CTS, na abordagem dos impactos ambientais gerados pelo consumo de produtos de higiene.

No primeiro momento pedagógico, realizado logo no início da oficina, ocorreu a problematização do tema por meio de algumas questões: Que tipo de lixo você gera? Você já pensou sobre a quantidade de lixo gerada diariamente? Para subsidiar a discussão, foram apresentados alguns dados sobre a produção do lixo no Estado de São Paulo, em outras regiões do Brasil e pelos países mais desenvolvidos (MÓL, et al., 2005).

Outras questões sobre os tipos de materiais que compõem o lixo também foram debatidas. Ao se considerar a composição das embalagens cartonadas, foi proposta a primeira atividade prática da oficina: os participantes receberam um pedaço de embalagem e foram desafiados a separar os materiais que a compunham. A atividade também causou surpresa, pois foram encontradas camadas de plástico em uma embalagem que, geralmente, é considerada como feita de papel. Os resultados obtidos pelos participantes foram socializados, abordandose outras informações sobre as características químicas das camadas encontradas, formadas por polietileno, papel e alumínio.

A partir disso, a embalagem foi classificada como resíduo sólido, lançando-se outras questões para debate: quais outros produtos que consumimos também geram esse tipo de resíduo? É importante conhecermos os resíduos que geramos? Por quê? E o que vai pelo ralo, também é lixo? É sólido? Será que descartamos produtos com substâncias prejudiciais ao meio ambiente e nem nos damos conta? A discussão foi orientada para a abordagem do impacto ambiental das microesferas. Foram exibidos os vídeos "A história das microesferas" (THE STORY OF MICROBEADS, 2015) e "Microplásticos e a poluição nos oceanos" (2016) e utilizadas reportagens para aprofundar a problematização. Além disso, foram apresentadas

\footnotetext{
\begin{tabular}{l|l}
\multirow{2}{*}{ REVISTA } & EXTENSÃO \& CIDADANIA \\
\cline { 2 - 3 } & v. 8, n. 14, p. 130-145, jul./dez. 2020. ISSN 2319-0566
\end{tabular}
} 
reclamações de consumidoras de esmaltes que alegavam que o efeito dégradé promovido por um esmalte era devido ao chumbo em sua composição, causando problemas com as unhas.

No segundo momento, organização do conhecimento (DELIZOICOV; ANGOTTI; PERNAMBUCO, 2011), quando os problemas apresentados são analisados sob a perspectiva científica, foram realizados dois experimentos. O primeiro experimento teve como objetivo separar e analisar as partículas sólidas de amostras de sabonetes esfoliantes quanto à sua forma, tamanho e composição, avaliando a possibilidade de serem microesferas de plásticos, que são descartadas pelo ralo. Com o segundo experimento, os participantes investigaram o efeito dégradé do esmalte, separando e analisando as partículas sólidas presentes em esmaltes que proporcionam esse efeito.

No momento da aplicação, os conhecimentos construídos anteriormente foram utilizados para analisar e compreender tanto as problematizações iniciais quanto novas situações problemas (DELIZOICOV; ANGOTTI; PERNAMBUCO, 2011). Assim, as atividades realizadas na oficina foram retomadas com os participantes. Chegando-se à conclusão de que as microesferas dos esfoliantes analisados eram feitas de plástico, foram discutidas alternativas para substituir esse material sem que a ação esfoliante do produto fosse perdida. Nesse contexto, foi apresentado um aplicativo para smartphones que, por meio da câmera, realiza a leitura do código de barras de diversos produtos e apresenta as informações sobre sua composição, indicando a presença de microesferas de plástico (PLASTIC SOUP FOUNDATION, 2017). Em relação ao segundo experimento, chegou-se à conclusão de que os compostos responsáveis pelo efeito dégradé não possuem chumbo em sua composição, o que gerou debates sobre quais seriam as possíveis razões dos danos provocados pelo esmalte.

$\mathrm{Na}$ finalização da oficina, foram analisadas reportagens sobre a presença de cafeína, colesterol, hormônios sexuais e medicamentos na água tratada e encaminhada para consumo. Assim, foram considerados possíveis trajetos percorridos por essas substâncias e as limitações dos tratamentos de água e das legislações vigentes em relação aos padrões de potabilidade da água. Diante disso, algumas ações diante dessas limitações foram propostas.

\section{Aproximações entre extensão, pesquisa e ensino}

Como é possível verificar nas descrições das atividades desenvolvidas, as oficinas abrangem situações de ensino e de aprendizagem, evidenciando sua aproximação com o ensino. 
As atividades propostas tiveram intencionalidade e foram planejadas coletivamente entre as monitoras e a docente responsável pelo projeto. Cabe destacar, no entanto, que as situações de aprendizagem não se restringem àquelas promovidas no momento da realização da oficina, nem se referem apenas à aprendizagem dos participantes. Mais do que isso, em todo o processo de criação da oficina foram construídos e mobilizados conhecimentos relacionados à ciência, à didática da ciência, a metodologias e estratégias de ensino e, consequentemente, à atuação docente. Segundo Severino (2007, p. 32), “é graças à extensão que o pedagógico ganha sua dimensão política, porque a formação do universitário pressupõe também uma inserção no social, despertando-o para o entendimento do papel de todo saber na instauração do social”. Esse processo foi percebido pelos licenciandos envolvidos e evidenciado em produções decorrentes das oficinas como relatórios, trabalhos de conclusão de curso e outras publicações (OLIVEIRA, 2016; BRANCHER, 2017; KEMCZINSKI, et al., 2018).

Na elaboração de todas as oficinas, foram levadas em consideração as características e as especificidades do conhecimento químico. Para Talanquer (2011), o conhecimento químico pode ser caracterizado por três principais formas: i) experiências, que se referem ao conhecimento empírico; ii) modelos, que compreendem os modelos teóricos explicativos, prescritivos e descritivos desenvolvidos na química para compreensão do mundo e iii) visualizações, que se referem às diversas representações utilizadas na área, como fórmulas, equações, desenhos, símbolos, gráficos, entre outros. Buscou-se contemplar essas três formas, utilizando-se experimentos investigativos e outras atividades práticas (experiências), as explicações sob o ponto de vista científico (modelos) e as representações, com linguagem própria dessa ciência (visualizações), de forma inter-relacionada com os temas abordados e as manifestações dos participantes.

Os conhecimentos científicos foram tratados partindo-se do macroscópico para o microscópico, de forma contextualizada e problematizada em situações reais e de importância social, política, econômica e ambiental. Isso foi possível pela consideração dos direcionamentos da pesquisa em ensino de ciências para o ensino de química na criação das oficinas, e esta foi a primeira aproximação do projeto de extensão com a pesquisa. A segunda aproximação se deu por meio dos trabalhos de pesquisa realizados após a realização das oficinas, quando foram estabelecidos problemas de pesquisa como: Como o ensino de química e as oficinas podem contribuir para a reflexão sobre a prática do consumo das pessoas? Quais são as contribuições da abordagem CTS realizada para instigar os participantes a refletirem e analisarem suas 
práticas de consumo? Quais são as contribuições da oficina para o processo de Alfabetização Científica e aprendizagem em química dos participantes?

Essas questões de pesquisa, assim como a contribuição das oficinas na formação docente, têm orientado a continuidade do projeto, mas sem perder seu caráter de extensão. Pessoas de diferentes idades, escolaridades e municípios vêm até à universidade com intenções, interesses e conhecimentos para participarem voluntariamente das oficinas, que tem se configurado como um espaço de reflexão sobre os problemas enfatizados e de troca de experiências. Os participantes da oficina, de modo geral, avaliaram positivamente, ao responderem questionários, a contribuição das oficinas para a aprendizagem de alguns conceitos científicos e para a reflexão sobre o consumo consciente e sobre as relações existentes entre a Ciência, Tecnologia e Sociedade.

\section{Considerações finais}

O desenvolvimento do projeto de oficinas temáticas tem indicado a potencialidade de ações dessa natureza na articulação entre extensão, pesquisa e ensino. Considerando o envolvimento de estudantes de cursos de licenciatura, tanto como participantes ou ministrantes das oficinas, essa articulação também contempla a formação de professores, principalmente, no que se refere ao desenvolvimento da contextualização, interdisciplinaridade, metodologias e estratégias para o ensino de ciências e de química. A inserção dos licenciandos envolvidos no projeto com os aspectos sociais ocorreu não só pelo seu contato com a comunidade externa, mas, também, pela própria natureza dos temas trabalhados nas oficinas.

Os temas escolhidos despertaram interesse da comunidade externa e interna da universidade, além de permitirem o desenvolvimento de atividades práticas e dinâmicas, de forma a superar formatos meramente expositivos de comunicação. Os conhecimentos químicos foram abordados de forma diferente daquela frequentemente realizada na educação formal, permitindo que pessoas de diferentes escolaridades entendessem suas contribuições para a compreensão do tema. Essa forma de abordagem tem inspirado o trabalho de licenciandos durante seus estágios supervisionados e na elaboração de trabalhos de conclusão de curso, reforçando o caráter articulador da pesquisa, ensino e extensão do projeto.

Cabe destacar, também, algumas dificuldades encontradas no desenvolvimento do projeto, que estiveram relacionadas ao fato de algumas pessoas se inscreverem, mas não 
comparecerem no dia da oficina, tirando a oportunidade de outras pessoas participarem, e a realização de atividades práticas apenas com materiais alternativos e de baixo custo, diante dos recursos insuficientes para aquisição de reagentes e vidrarias.

\section{Referências}

ABIHPEC. Panorama do setor de higiene pessoal, perfumaria e cosméticos. Disponível em: goo.gl/BSN1be. Acesso em: 14 nov. 2016.

BRANCHER, R. Proposta de oficina temática sobre a química do álcool. 29f. Monografia (Graduação em Química) - Universidade Federal de São Carlos, São Carlos, 2017.

CACHAPUZ, A.; GIL-PEREZ, D.; CARVALHO, A. M.; PRAIA, J,; VILCHES (org.). A necessária renovação do ensino de ciências. São Paulo: Cortez, 2005.

CRUZ, A. A. C.; RIBEIRO, V. G. P.; LONGHINOTTI, E.; MAZZETTO, S. E. A Ciência Forense no ensino de química por meio da experimentação investigativa e lúdica. Química Nova na Escola, v.38, n. 2, p.167-172, maio 2016.

DELIZOICOV, D.; ANGOTTI, J. A. P.; PERNAMBUCO, M. M. C. A. Ensino de Ciências: fundamentos e métodos. 4. ed. São Paulo: Cortez, 2011.

FOLHA DE SÃO PAULO. PC Farias, 20 anos: o crime que abalou o país. 2016. Disponível em: goo.gl/mYAdGY. Acesso em: 20 jul. 2016.

FOUREZ, G. Alfabetización científica y tecnológica: acerca de las finalidades de la enseñanza de las ciencias. Buenos Aires: Colihue, 2005.

GOHN, M. G. Educação não-formal, participação da sociedade civil e estruturas colegiadas nas escolas. Ensaio: Avaliação e Políticas Públicas em Educação, v.14, n.50, p. 27-38, 2006.

KEMCZINSKI, A. R.; DO NASCIMENTO, J. U.; ORTOLANI, T. S.; ROCHA, V. M.; FURLAN, E. G. M.; MILARÉ, T. Atividades investigativas: a formação de professores no contexto da EJA. Crítica Educativa, v.3, n.3, p. 214-229, 2018.

LIMA, R.; E FRACETO, L. F. Abordagem Química na extração de DNA de Tomate.

Química Nova na Escola, n.25, p.43-45, maio 2007.

LISBÔA, J. C. F. Investigando tintas de canetas utilizando cromatografia em papel. Química Nova na Escola, n.7, p.38-39, maio 1998.

LORENZETTI, L.; DELIZOICOV, D. Alfabetização científica no contexto das séries iniciais. Ensaio - Pesquisa em Educação em Ciências, v. 3, n. 1, jun. 2001. 
MANUAL DO MUNDO. Como fazer luz negra caseira usando celular. 2015. Disponível em: http://www.manualdomundo.com.br/2015/01/como-fazer-luz-negra-caseira-usandocelular/. Acesso em: 10 abr. 2016.

MANUAL DO MUNDO. Carta secreta com limão. 2008. Disponível em: http://www.manualdomundo.com.br/2008/07/carta-secreta-com-limao/. Acesso em: 10 abr. 2016.

MARCO, B. La alfabetización científica. In: PALACIOS, F. J. P.; LÉON, P. C. de. Didáctica de las Ciências Experimentales. Alcoy, España: Marfil, 2000. p.141-164.

MARCONDES, M. E. R. Proposições metodológicas para o ensino de química: oficinas temáticas para a aprendizagem da ciência e o desenvolvimento da cidadania. Em Extensão, v.7, p. 67-77, 2008.

MICROPLÁSTICOS E A POLUIÇÃO NOS OCEANOS. Minuto da Terra. Brasil, 2016. Vídeo (2 min 53 s). Disponível em: https://www.youtube.com/watch?v=adc0cOqE4qs. Acesso em: 9 out. 2017.

MÓL, G. S.; SANTOS, W. L. P.; CASTRO, E. N. F.; SILVA, G. S.; MATSUNAGA, R. T.; SILVA, R. R.; FARIAS, S. B.; SANTOS, S. M. O.; DIB, S. M. F. Química e sociedade. São Paulo: Nova Geração, 2005.

MUITO ALÉM DO PESO. Maria Farinha.Brasil, 2012. Vídeo (84 min). Disponível em: https:http://www.muitoalemdopeso.com.br. Acesso em: 10 jul. 2018.

OLIVEIRA, A.C.D. Química, consumismo e cosméticos: uma oficina temática com abordagem CTS. 76f. Monografia (Graduação em Química) - Universidade Federal de São Carlos, São Carlos, 2016.

PAZINATO, M. S.; BRAIBANTE, M. E. F. Oficina temática composição química dos alimentos: uma possibilidade para o ensino de química. Química Nova na Escola, v. 36, n. 4, p. 289-296, 2014.

PLASTIC SOUP FOUNDATION. Beat the Microbead. Versão 2.4, atualização dezembro de 2017. Disponível em: http://www.beatthemicrobead.org/. Acesso em: 10 mar. 2018.

SALADA ATÔMICA. Química forense: pó caseiro revelador de digitais, 2015. Vídeo (5 min). Disponível em: goo.gl/rdyuhK. Acesso em: 10 abr. 2016.

SANTOS, M. P. Extensão Universitária: espaço de aprendizagem profissional e suas relações com o ensino e a pesquisa na educação superior. Extensio: Revista Eletrônica de Extensão, Florianópolis, v. 11, n. 18, p. 36-52, nov. 2014.

SANTOS, W. L. P.; MORTIMER, E. F. Tomada de decisão para ação social responsável no ensino de ciências. Ciência \& Educação, Bauru, v.7, n.1, p. 95-111, 2001.

SANTOS, W. L. P.; SCHNETZLER, R. P. Educação em química: compromisso com a

$$
\begin{array}{l|l}
\multirow{2}{*}{\text { REVISTA }} & \text { EXTENSÃO \& CIDADANIA } \\
\cline { 2 - 3 } & \text { v. 8, n. 14, p. 130-145, jul./dez. 2020. ISSN 2319-0566 }
\end{array}
$$


cidadania. 4. ed. rev. atual. Ijuí: Ed. da Unijuí, 2015.

SEVERINO, A. J. Metodologia do trabalho científico. 23. ed. São Paulo: Cortez, 2007.

SHEN, B. S. P. Science Literacy. American Scientist, v. 63, p. 265-268, may/jun 1975.

SILVA, P. S; ROSA, M. F. Utilização da ciência forense do seriado CSI no ensino de química. Revista Brasileira de Ensino de Ciência e Tecnologia, v.6, p.148-160, 2013.

TALANQUER, V. Macro, Submicro, and Symbolic? The Many Faces of the Chemistry Triplet. International Journal of Science Education, v. 33, n. 2, p.179-195, 2011.

THE STORY OF COSMETICS. Story of Stuff Project. California, USA, 2010.

Vídeo(8m17s). Disponível em: goo.gl/QxoXNt. Acesso em: 10 jun. 2016.

THE STORY OF MICROBEADS. Story of Stuff Project. California, USA, 2015. Vídeo (2 min). Disponível em: https://storyofstuff.org/movies/. Acesso em: 10 out. 2017.

TUDO SE TRANSFORMA, HISTÓRIA DA QUÍMICA, QUÍMICA FORENSE. Ccead

PUC-Rio, Rio de Janeiro-SJ, Brasil, 2012. Vídeo (13 min 22 s). Disponível em:

https://www.youtube.com/watch?v=KnwxyBORQkI. Acesso em: 10 nov. 2020.

Recebido em: 6 de julho de 2018. Aceito em: 13 de novembro de 2020. 